\title{
User Experience Aspects and Dimensions: Systematic Literature Review
}

\author{
Mohammad Zarour and Mubarak Alharbi
}

\begin{abstract}
Technology is changing the way we used to live. The new generation, indisputably, is the generation of technology. Mobile applications have become one of the most used products on mobile devices. Nowadays, the users of technology applications started developing their user experience very early in their lives! The success or failure of a software product is affected by the users of that product. Accordingly, studying, measuring and improving user experience is crucial for the success of the any software product. This paper is documenting a systematic literature review to identify various user experience dimensions and aspects that need to be considered when evaluating the user experience.
\end{abstract}

Index Terms - User experience dimensions, user experience evaluation, mobile application, systematic literature review.

\section{INTRODUCTION}

Technology is changing the way we used to live. The new generation, indisputably, is the generation of technology. Nowadays, the users of technology applications started developing their user experience very early in their lives! One of the very popular type of applications used are those running by mobile devices. Mobile applications have become some of the most-used products on mobile devices [1], and $90 \%$ of the time on mobile internet has been spent using applications [2].

Accordingly, it is important to make sure that these applications continue to satisfy the users' needs. Satisfying the users' needs from the functionality perspective and its ease of use, efficiency, and learnability is a usability concept. Understanding the users' needs from the perspectives of what they do and what they need in addition to considering their emotional responses is known as user experience [3]. Evaluating the user experience is considered as the fifth generation of product evaluation in the domain of humancomputer interaction (HCI) which is started late in the 1990s [4], [5].

User experience (UX) studies in HCI fields have increased during last two decades [5]. In these studies, a common agreement has been reached about the dynamics of user experience and the subjectivity of its nature [6].

Several studies have stated that user experience is dynamic, context-dependent, and subjective [7]. Due to this fact, the user experience is seen as something desirable,

Manuscript received August 7, 2017; revised November 20, 2017.

M. Zarour is with Prince Sultan University, Riyadh, 11586 KSA (e-mail: mzarour@psu.edu.sa).

M. Alharbi is with Alwatania Information Systems (Wi-Sys), Riyadh, KSA (e-mail: alhoymli@gmail.com). without defining what "something" means, and this has led to difficulty in agreeing on a user experience definition [7] and on how to measure it [8]. In literature, suggested definitions for user experience are proposed, but those definitions were affected by the researcher's background and interest [7] and couldn't be used as a common definition. On the other hand, ISO 9241-210 has a promising definition of user experience; where it defines user experience as "A person's perceptions and responses that result from the use or anticipated use of a product, system or service" [9]. This definition is in line with the view of most researchers about the subjectivity of UX, but the used terms require more explanation to list all possible objects that affect user experience [7]. Hence, there is a need to elaborate more on defining user experience and the related aspects and dimensions needed to build a general framework of UX evaluation.

The paper is structured as follows. Section II presents the process we followed to conduct the systematic literature review. It details the research questions addressed, how the search was performed, the classification scheme used, and how the data was extracted and analyzed. Section III presents review results obtained. Section IV presents the synthesis of collected results. Section V summarizes the threats to validity we identified in our work and how they were addressed. Section VI summarizes the conclusions and future work.

\section{SySTEMATIC LITERATURE REVIEW}

Evidence-Based Software Engineering (EBSE) is aiming "to provide the means by which current best evidences from research can be integrated with practical experience and human values in the decision-making process regarding the development and maintenance of software" [10]. One of the approaches used to achieve this is conducting systematic literature review (SLR). The goal of systematic literature review is to provide an overview of the results available within certain domain to provide better understating of its related issues.

In this paper, we aim to explore systematically, based on published research, the domain of UX to identify dimensions that have an impact on the UX. Identifying these dimensions will build boundaries around the UX and will give directions on how to recognize the impact on the UX if it exists. We have conducted a systematic review based on the guidelines provided in [11].

\section{A. The Need for a Systematic Review}

A systematic literature review is needed to explore and 
assess the status and the work that has done in the user experience field. This SLR explores all relevant dimensions and aspects that have an impact on user experience as the user experience is considered as a part of satisfying the users' needs [3]. Due to the numerous studies that are conducted in UX field, synthesizing these studies using SLR is prominent.

\section{B. Define Research Questions}

The research questions that we are going to seek answers for are as follows:

RQ1: What are the different definitions of user experience in literature?

This question concerned with identifying all possible definitions of UX in literature, either defined by authors or any specialized organizations such as ISO. Identifying those definitions will guide us in extracting the general dimensions of the aspects that affect the UX, and this will help us to discover the relationship between the aspects (see Table I).

\section{RQ2: What are the aspects that affect the user experience?}

This question concerned with identifying the aspects that affect the UX, which have been studied or discovered in literature. Identifying these aspects, in addition to relating them to the study domain and the UX dimensions, will help us to study the effects of these aspects on the UX (see Table I).

TABLE I: RESEARCH QUESTIONS AND THE EXPECTED OUTCOMES

\begin{tabular}{|c|l|l|}
\hline $\begin{array}{c}\text { Research } \\
\text { Question }\end{array}$ & \multicolumn{1}{|c|}{ Expected Outcomes } & Value for the study \\
\hline RQ1 & UX dimensions & $\begin{array}{l}\text { Gather all possible } \\
\text { dimensions. }\end{array}$ \\
\hline RQ2 & $\begin{array}{l}\text { The aspects that affect } \\
\text { the UX and the relation } \\
\text { to UX dimensions }\end{array}$ & $\begin{array}{l}\text { Gather all affections } \\
\text { aspects. }\end{array}$ \\
\hline
\end{tabular}

\section{Search for Primary Studies}

To search for the primary studies, we need to define the search terms to be used in our search. The search terms are derived from the research questions. The corresponding search terms and their synonyms are used then to conduct the search (see Table II).

TABLE II: RESEARCH QUESTIONS AND THE EXTRACTED KEYWORDS
\begin{tabular}{|l|l|}
\hline $\begin{array}{l}\text { Research } \\
\text { Question }\end{array}$ & Extracted Search Terms \\
\hline RQ1 & $\begin{array}{l}\text { User experience, user experience definition, customer } \\
\text { experience, customer experience definition }\end{array}$ \\
\hline RQ2 & User experience aspects, customer experience aspects \\
\hline
\end{tabular}

Four main digital libraries are used to conduct the search. This includes IEEE, ACM, Citeseer and Google Scholar. The libraries are searched for publications that are published in the period from 2005 till August-2015. To retrieve relevant papers that are focusing on our study domain, we searched the publications' title and keywords for the specified search terms. Applying the search terms has retrieved 2331 across all sources (see Table III).
TABLE III: RESULTS OF REMOVING THE DUPLICATES FROM THE SOURCES

\begin{tabular}{|l|c|c|c|c|c|}
\hline $\begin{array}{l}\text { RQ/ } \\
\text { Source }\end{array}$ & IEEE & ACM & Citeseer & $\begin{array}{l}\text { Google } \\
\text { Scholar }\end{array}$ & Total \\
\hline RQ1 & 574 & 1464 & 254 & 39 & 2331 \\
\hline RQ2 & 5 & & & \\
\hline
\end{tabular}

\section{1) Inclusion criteria}

The inclusion criteria will focus on the factors and conditions that need to exist so that we can select the paper and include it in the primary studies list. The criteria are mentioned below:

1) The paper answers one of the RQs, either with a fully or a partially.

2) The paper's publication date is 2005 and above.

3) If a snowballing search happened, then the paper should exist on one of the primary sources (IEEE, ACM, Citeseer, or Google Scholar).

\section{2) Exclusion criteria}

The exclusion criteria will focus on the factors and conditions that cause the paper to be excluded from the primary studies list. The criteria are mentioned below:

1) The paper's publication date is before 2005 .

2) Full paper is not accessible

3) The paper limited to the non-IT domain.

4) The paper's author is not known.

5) The paper is calling for a workshop.

6) It is a book or magazine.

7) The paper is not answering any RQs, either with fully or partially.

8) The paper is a duplicate of another paper with a different title, where we choose the most recent one.

To reach an accurate result and to minimize the duplication, we retrieved the papers that answered one RQ or both in each source, and this was done using the OR condition between the search terms. Depending on the application domains that the paper is conducted in; we chose the papers that related to the UX domain and its focus is software and technology. Within this scanning, we discovered that there were duplicates inside some sources because the papers' titles were different while the papers' contents or contribution were almost the same, hence, we chose the most recent paper. Table IV summarizes the resulted set of papers per digital library that included in this study.

TABLE IV: RESULTS OF APPLYING THE INCLUSION/EXCLUSION CRITERIA

\begin{tabular}{|c|c|c|c|c|c|}
\hline $\begin{array}{c}\text { RQ/ } \\
\text { Sourc } \\
\mathrm{e}\end{array}$ & IEEE & ACM & Citeseer & $\begin{array}{c}\text { Google } \\
\text { Scholar }\end{array}$ & Total \\
\hline RQs & 59 & 119 & 67 & 8 & 253 \\
\hline
\end{tabular}

To store the selected papers and review them carefully, we used the Mendeley reference management tool. This tool has its DB, and there was an ability to retrieve any papers related to the known papers. This feature has added to our known papers seven more papers that related to the UX domain, and we retrieved those papers from our primary sources (ACM and Google Scholar) and noticed that those papers did not have any keywords from the search keywords 
that were extracted from the RQs. Table V summarizes the final accepted papers that related to the UX domain as per the conditions above.

TABLE V: New Results Using MENDELEy DB to Find Related PaPERS

\begin{tabular}{|c|c|c|c|c|c|}
\hline $\begin{array}{c}\mathrm{RQ} / \\
\text { Source }\end{array}$ & IEEE & ACM & Citeseer & $\begin{array}{c}\text { Google } \\
\text { Scholar }\end{array}$ & Total \\
\hline RQs & 59 & 124 & 67 & 10 & 260 \\
\hline
\end{tabular}

Table VI shows the final number of papers from the previous stage after applying inclusion and exclusion criteria.

TABLE VI: INCLUDED AND EXCLUDED STUDIES ACROSS THE SOURCES
\begin{tabular}{|c|c|c|c|c|c|}
\hline Criteria & IEEE & ACM & Citeseer & $\begin{array}{c}\text { Google } \\
\text { Scholar }\end{array}$ & Total \\
\hline $\begin{array}{c}\text { Included } \\
\text { Papers }\end{array}$ & 26 & 68 & 15 & 5 & 114 \\
\hline $\begin{array}{c}\text { Excluded } \\
\text { Papers }\end{array}$ & 33 & 56 & 52 & 5 & 146 \\
\hline Total & 59 & 124 & 67 & 10 & 260 \\
\hline
\end{tabular}

So, the total number of primary studies becomes 114 after applying the inclusion and exclusion criteria. All studies' meta-data, either included or excluded, have been updated so we can extract the data about it during the data synthesis stage. For more details about the primary studies, refer to [12].

\section{Data Extraction Strategy}

In this phase, after selecting the primary studies, we will extract the data that will be used in the data analyzing stage. Table VII summarizes the extracted attributes from each selected study and the expected values for each one.

\begin{tabular}{|c|c|c|}
\hline Attribute & Description & Values \\
\hline Title & The paper's title & \\
\hline Source & $\begin{array}{l}\text { The digital source for this } \\
\text { paper }\end{array}$ & $\begin{array}{l}\text { IEEE, ACM, Citeseer, } \\
\text { Google Scholar }\end{array}$ \\
\hline Authors & The paper's authors & \\
\hline $\begin{array}{l}\text { Publishing } \\
\text { Date }\end{array}$ & $\begin{array}{l}\text { The date of publishing the } \\
\text { paper }\end{array}$ & $2005,2006, \ldots, 2014$ \\
\hline Country & $\begin{array}{l}\text { The country where this } \\
\text { paper was published }\end{array}$ & $\begin{array}{l}\text { We rely on city } \\
\text { attributes } \\
\text { Mendeley, but when } \\
\text { this attribute is not } \\
\text { available, we select } \\
\text { the first author's } \\
\text { country as per his } \\
\text { email or country } \\
\text { name in the paper. }\end{array}$ \\
\hline $\begin{array}{l}\text { Answered } \\
\text { RQs }\end{array}$ & $\begin{array}{l}\text { The research questions } \\
\text { (RQs) that have been } \\
\text { answered in this paper. }\end{array}$ & RQ1, RQ2, \\
\hline $\begin{array}{l}\text { Applicatio } \\
\text { n Domain }\end{array}$ & $\begin{array}{l}\text { The domain that this } \\
\text { paper has studied }\end{array}$ & $\begin{array}{l}\text { General, Software, } \\
\text { Mobile, etc. }\end{array}$ \\
\hline $\begin{array}{l}\text { Study } \\
\text { Participant } \\
\text { s }\end{array}$ & $\begin{array}{l}\text { This attribute identifies } \\
\text { who participated in this } \\
\text { paper }\end{array}$ & $\begin{array}{l}\text { Academia, Industry, } \\
\text { or Mixed }\end{array}$ \\
\hline $\begin{array}{l}\text { Research } \\
\text { Output }\end{array}$ & $\begin{array}{l}\text { What is the type of output } \\
\text { from this paper? }\end{array}$ & $\begin{array}{l}\text { New Framework, } \\
\text { New Model, Usage of }\end{array}$ \\
\hline
\end{tabular}

\begin{tabular}{|l|l|l|}
\hline & & $\begin{array}{l}\text { technique, usage of } \\
\text { the tool, etc. }\end{array}$ \\
\hline $\begin{array}{l}\text { UX } \\
\text { Definition }\end{array}$ & $\begin{array}{l}\text { The UX definition that } \\
\text { was proposed in this } \\
\text { paper }\end{array}$ & \\
\hline $\begin{array}{l}\text { UX } \\
\text { Desearch }\end{array}$ & $\begin{array}{l}\text { The research disciplines } \\
\text { that the paper focuses on }\end{array}$ & $\begin{array}{l}\text { Value, Technology, } \\
\text { User, etc. }\end{array}$ \\
\hline $\begin{array}{l}\text { UX } \\
\text { Aspects }\end{array}$ & $\begin{array}{l}\text { The aspects that are } \\
\text { mentioned in the paper } \\
\text { and that have impacted on } \\
\text { the UX levels }\end{array}$ & $\begin{array}{l}\text { Emotions, usability, } \\
\text { functionality, visual } \\
\text { attractiveness, etc. }\end{array}$ \\
\hline
\end{tabular}

\section{DEMOGRAPHIC RESULTS}

As a result of conducting the SLR stages, we analyzed the extracted data from the primary studies, and we generated charts that explain the trends that related to those extracted data.

\section{A. Source}

We used four main sources in this SLR, which are IEEE, ACM, Citeseer, and Google Scholar. Most of the selected papers were from the ACM digital library, then IEEE, then Citeseer, and finally Google Scholar. We found that most of the publications are published mainly through ACM followed by IEEE, other publications channels follow.

We tried to avoid any use of external links that were not considered to be digital libraries (see Fig. 1).

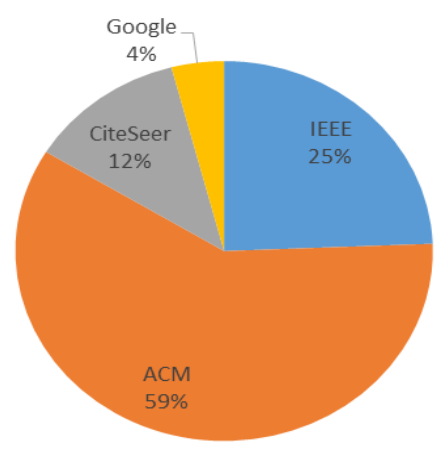

Fig. 1. Sources of selected studies.

\section{B. Publishing Date}

In this SLR, we selected the primary studies that related to the research topic that published from 2005 till August-2015. As noticed in Fig. 2, the publishing in this SLR domain as per the agreed inclusion and exclusion criteria grew over the last ten years.

\section{\# of Papers}

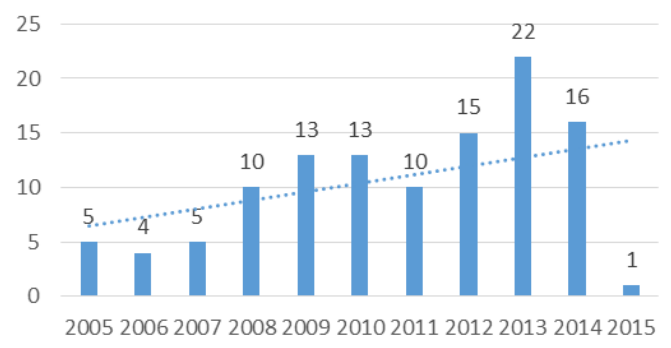

Fig. 2. The growth of published studies in the UX domain. 
The trend referring to the growth and the percentage is a high number. Since 2008, the publishing in this area is increasing, and this explains the need for these UX-related topics. 2015 has only 1 selected primary paper, and this is due to the inclusion and exclusion criteria. Publications in 2015 was in the same level of previous years, but the topics focused more on domains related to the process, e.g. "Relating UX activities to CMMI and Agile methodologies" [11] which makes them out of the scope of this study.

\section{Country and Sectors' Participations}

As per the conditions of extracting the countries of the primary studies in the previous stage, Fig. 5 explains and shows that most of the primary studies were in the USA, by $24 \%$, followed by the European countries. A few papers were from the Asian countries and South American countries In the USA, which has the high percentage of the studies $(24 \%)$, the academia's participation was $82.8 \%$, while the industry's involvement was $3.4 \%$ and the mixed participation between them was $13.8 \%$. Finland, with $20 \%$, came to the top of the European countries and was the second country after the USA. The industry participation was higher than the USA's industry participation, and it was $12 \%$, while the mixed involvement and the academia were $12 \%$ and $76 \%$, respectively.

The reason behind this high percentage of industry participation in Finland was the full participation of Nokia for both the industry percentage and the mixed percentage. The period of this participation was between 2008 and 2010, and there was nothing after that. Fig. 3 shows the percentages of primary studies across the countries.

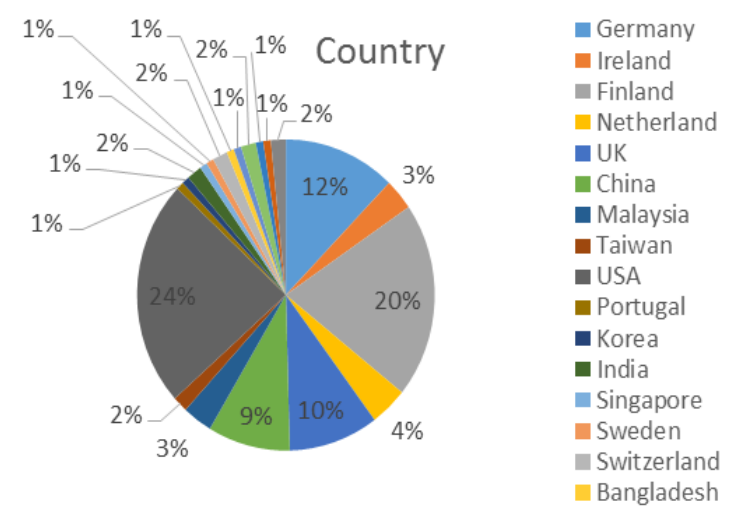

Fig. 3. Participation of countries in UX research.

\section{Answered RQs}

From the previous stage - data extracting - we identified the answered research questions (RQs) in each primary study, and the below chart will explain the percentages of each answered RQ.

From the chart in Fig. 4, we noticed that most of the primary studies $(58 \%)$ have answered the second research question (RQ2). The question was about identifying the factors that affect the user experience (UX). Those factors are related to the study's domain itself but can be applied to any other domain, either fully or partially. The remaining percentage is related general related papers that speaking about the methods that used to evaluate UX and some frameworks used to measure and control UX activities.
These papers will be used to get more understanding about related UX subjects.

\section{\# of papers answered RQs}

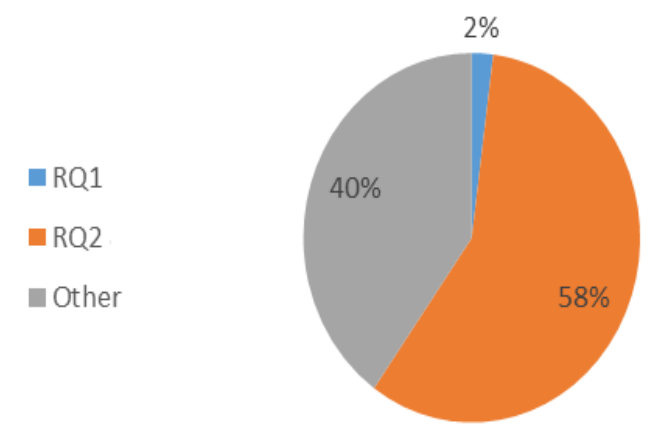

Fig. 4. Percentage of answered research questions in selected studies.

\section{E. Application Domain}

Application domains that have been explored in this SLR are shown in Fig. 5. The figure shows that most of primary studies done without the limitation to a particular domain, which was $51 \%$, and we identified this as a general domain. In addition to the general domain, we explored the studies that related to domains similar to the mobile application from a development perspective; such as web portals and from the point of view of affecting the mobile application such as Mobile Communication.

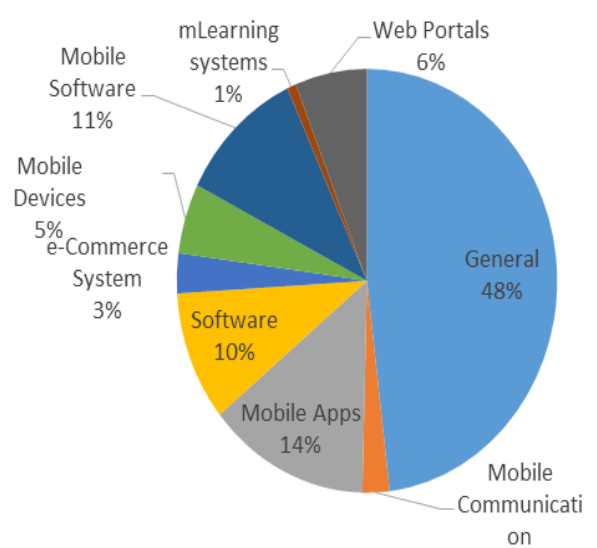

Fig. 5. Application domains that have been studied in relation with UX.

\section{F. Research Output}

The research output from the primary studies in this SLR is shown in the below chart. It was noticed that the majority was about guidelines and emphasizing the factors that need to be considered when evaluating the UX.

The percentage for the guidelines was $44 \%$, while the new suggested frameworks, models (methods), tools, and techniques (ways of using the factor or the method) were $18 \%, 17 \%, 3 \%$, and $1 \%$, respectively.

The usage experiences of techniques, tools, and models, were $3 \%, 3 \%$, and $2 \%$, respectively.

The remaining percentage was $1 \%$, and it was for a modification of current techniques to use a method to evaluate a factor of user experience (see Fig. 6). 


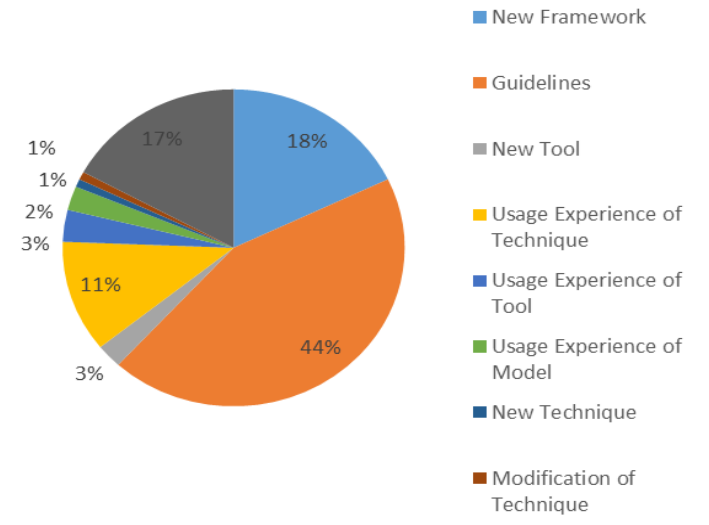

Fig. 6. Output of selected studies.

\section{RESULTS SYNTHESIS}

\section{A. UX Definitions}

ISO 9241-210 [9] has defined UX as "A person's perceptions and responses that result from the use or anticipated use of a product, system or service". A survey that gathered a view of UX from 275 researchers has been conducted in [7]. It is concluded that: " the draft UX definition by ISO is a promising one, but the used terms and the list of the possible objects of UX will require further explanations, e.g., 'anticipated use"" [7]. In 2010, the ISO 9241-210 definition was confirmed and published. Hassenzahl defined the UX [13] as "A momentary, primarily evaluative feeling (good-bad) while interacting with a product or service". Hassenzahl's definition focused on evaluating feelings while interacting with the product. Schulze defined the UX in [14] as: "The degree of positive or negative emotions that can be experienced by a particular user in a specific context during and after product use and that motivates for further usage." Schulze's definition focused on the emotions felt while interacting with the product.

For each UX's definition, there are one or more elements that build the UX definition, and the main element that identified from the UX survey [7] is the Perspective. Perspective will help identify what and who has been affected by the changes of the UX and below are the UX Perspectives that are taken from the UX definitions [7]:

1) Organization: concerned about designing a good UX of its products

2) User: concerned about emotions (feelings) and usability.

3) Value: concerned about gained values

4) Design: concerned about product look and its experience's quality.

5) Evaluation: concerned about the context of use and how to evaluate it.

To identify the relationships between the above perspectives and the UX impact, we considered what stated in many studies that the main components of interaction between technology and user are (system or product, user, and the context of use) [1], [15], [16], see Fig. 9.

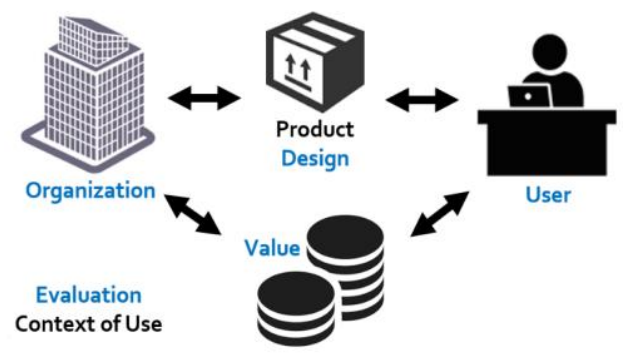

Fig. 7. Perspectives relationship.

From Fig. 7, we can conclude that the UX-related elements are:

1) $\mathrm{UX} \rightarrow$ Organization: This will look to provide valuable products for the users.

2) UX $\rightarrow$ User: This is the person who is looking for a valuable and efficient usage of the product.

3) UX $\rightarrow$ Context of use: This has an impact on both elements (organization and user) and which is the intermediate bridge between them.

4) UX $\rightarrow$ Product: This is concerned the product design.

So, as a summary of what we have analyzed, the UX is a value centric and all UX elements related to the value.

\section{B. UX Research Disciplines}

In this SLR, we found that the researchers focused on different disciplines depending on their background or their purpose for the study and below are the main disciplines that studied in this SLR:

1) UX and values: This is related to the impact of the UX's level on one of the below parts [15], [17]-[19]:

a. User's value from using the product.

b. Organization's value from providing the product to the users.

c. Conditional values that are related to the context of use and linked to the user or company or both.

2) UX and brand: This is related to the image of the organization or the marketing of the products and how the UX got affected by them [1], [15], [18].

3) UX and user's needs: This is related to the two types (Pragmatic \& Hedonic) of needs of the user and how satisfying the users will lead to a change in UX's level [8], [14], [15], [20]-[23].

4) UX and development process: This is related to the impact of the development process on UX [23], [24].

5) UX and technologies: This is related to the technologies that have been used to deliver the product, the level of operation after releasing the product to the users, and how the provided operation may affect the UX's level [1], [14], [18], [22], [25].

TABLE VIII: SUGGESTED DIMENSIONS FOR RESEARCH DISCIPLINES

\begin{tabular}{|c|c|}
\hline Discipline & Dimension \\
\hline Values \& Experience & Value \& Overall Experience (VX) \\
\hline Brand \& Experience & $\begin{array}{l}\text { Organization Brand Experience } \\
(\mathrm{BX})\end{array}$ \\
\hline $\begin{array}{l}\text { User Needs \& } \\
\text { Experience }\end{array}$ & User Experience (UX) \\
\hline $\begin{array}{l}\text { Development Process } \\
\text { \& Experience }\end{array}$ & Technology Experience (TX) \\
\hline $\begin{array}{l}\text { Technologies } \quad \& \\
\text { Experience }\end{array}$ & Technology Experience (TX) \\
\hline
\end{tabular}


Table VIII suggested several dimensions that cover these disciplines. Fig. 10 explains the relationship between disciplines and related dimension.

Taking into consideration the UX definitions' elements from the previous section, another dimension needs to be added, which is Context. Context is a dimension that covers the interaction between all other dimensions (as illustrated in Table VIIIand shown in Fig. 8).

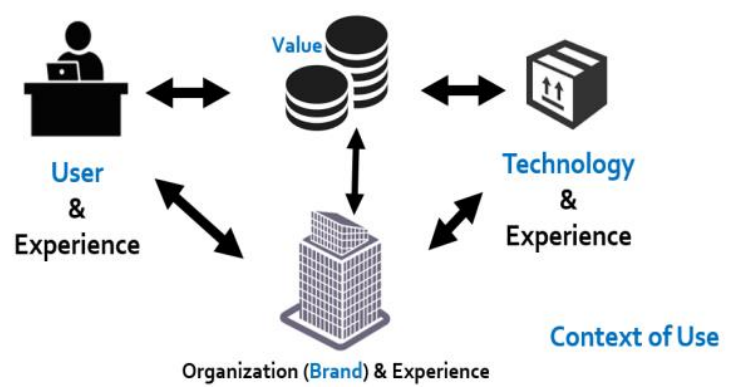

Fig. 8. Identified dimensions from the SLR and its relationships.

\section{UX Aspects}

From this SLR, we identified the main UX aspects that have been mentioned in the primary studies which have a direct or indirect impact on the UX [14]. These aspects are related to either the user himself, the system that is providing the service or the context of use between them. Those three components building the relation between the user and the system [1], [15], [16]. We tried to use the same terms that have been used in these primary studies as much as possible to keep the same terminologies.

Moreover, in this SLR we identified the term Pragmatic quality which is related to doing the task itself [26] such as usability; while the term Hedonic related to the expression of self and user's personal values [27] such as emotions. The user's related aspects can be either related to achieving explicit goals which are pragmatic aspects, or achieving implicit goals which are hedonic aspects. Fig. 9 explains all aspects and the number of papers that mentioned it.

Taking into consideration the UX dimensions, we found that the aspects that affect the UX can be categorized into one of the following types:

1) User's needs aspects: which is related to the "User" dimension and can be divided into two categories [27], [28]:

a. Pragmatic aspects: This is related to the "usability" and "do-goal" qualities.

b. Hedonic aspects: This is related to the "stimulation" and "be-goal" qualities.

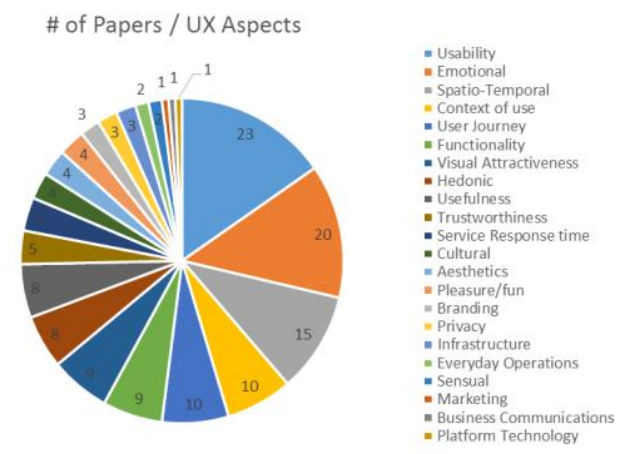

Fig. 9. UX aspects and the number of studies that relate to it in this SLR.
2) Brand aspects: This is related to the marketing and the business communications between the user and the organization and can be linked to the "Organization Brand" dimension.

3) Technology aspects: This is related to the development and production technologies that have an impact on the overall experience and can be linked to the "Technology" dimension. It can be divided into four types:

a. UX designs (UXD) aspects: related to the UI designs.

b. Development technology aspects: related to development technologies that are used in delivering the product.

c. Hardware aspects: related to the infrastructure of either the client side or the server side.

d. Operation aspects: related to the technologies that are used to monitor the production and response to the users.

4) Context aspects: This is related to any quality that is not related to one of the previous aspects but has an impact on them and can be linked to the "Context" dimension.

From the previous classifications and the identified UX aspects from the primary studies, Table IX illustrates the relationship between the UX aspects and its categories.

TABLE IX: SUGGESTED CATEGORIES FOR UX ASPECTS AND THEIR RELATIONSHIP TO UX DIMENSIONS

\begin{tabular}{|c|c|c|}
\hline UX Aspect & $\begin{array}{c}\text { Aspect } \\
\text { Category }\end{array}$ & Dimension \\
\hline Branding & Brand & Brand Experience ( BX) \\
\hline $\begin{array}{l}\text { Everyday } \\
\text { Operations }\end{array}$ & Brand & Brand Experience ( $\mathrm{BX}$ ) \\
\hline Marketing & Brand & Brand Experience ( BX) \\
\hline $\begin{array}{l}\text { Business } \\
\text { Communications }\end{array}$ & Brand & Brand Experience ( $\mathrm{BX}$ ) \\
\hline Context of use & Context & Brand Experience ( BX) \\
\hline Spatio-Temporal & Context & Brand Experience ( BX) \\
\hline User Journey & Context & Brand Experience ( $\mathrm{BX}$ ) \\
\hline Cultural & Context & User Experience (UX) \\
\hline Emotional & Hedonic & User Experience (UX) \\
\hline Hedonic & Hedonic & User Experience (UX) \\
\hline Trustworthiness & Hedonic & User Experience (UX) \\
\hline Aesthetics & Hedonic & User Experience (UX) \\
\hline Fun & Hedonic & User Experience (UX) \\
\hline Privacy & Hedonic & User Experience (UX) \\
\hline Sensual & Hedonic & User Experience (UX) \\
\hline Usability & Pragmatic & User Experience (UX) \\
\hline Functionality & Pragmatic & User Experience (UX) \\
\hline Usefulness & Pragmatic & User Experience (UX) \\
\hline $\begin{array}{l}\text { Platform } \\
\text { Technology }\end{array}$ & $\begin{array}{c}\text { Developme } \\
\text { nt } \\
\text { Technology }\end{array}$ & $\begin{array}{c}\text { Technology Experience } \\
\text { (TX) }\end{array}$ \\
\hline Infrastructure & Hardware & $\begin{array}{c}\text { Technology Experience } \\
\text { (TX) }\end{array}$ \\
\hline $\begin{array}{l}\text { Service Response } \\
\text { time }\end{array}$ & Operation & $\begin{array}{c}\text { Technology Experience } \\
\text { (TX) }\end{array}$ \\
\hline $\begin{array}{l}\text { Visual } \\
\text { Attractiveness }\end{array}$ & UXD & $\begin{array}{c}\text { Technology Experience } \\
\text { (TX) }\end{array}$ \\
\hline
\end{tabular}




\section{VALIDITY THREATS}

In this section, the possible threats and how to minimize their impact will be discussed.

Study search bias: some relevant publications may be missed which affects the completeness of the study. To reduce the effect of this threat, the researchers have searched four digital libraries which are well known and relevant as sources for software engineering and computer science publishing [29], the collected primary studies have been recorded using Mendeley reference management tool and to improve the results of the search, we have used one of the services provided by this management tool and look for related publications and were able to add 7 more publications based on this service and this makes the retrieved papers more complete.

Study selection bias: To enhance the reproducibility of the selected studies in this SLR, we have established a clear review protocol that defines the search terms, search sources, inclusion and exclusion criteria to select the primary studies. As different researchers can have different understandings that may result in drawing different conclusions, and to reduce any variation between the researchers in selecting primary studies, a multiple revision strategy was used.

Data extraction bias: data extraction may be negatively affected by the researcher's bias when extracting the data. To reduce such bias, a list of meta-data attributes has been identified and used to direct the data collection process. Moreover, extensive discussions between researchers on the extracted data were conducted to improve the correctness as well as the consistency of the collected data.

Data synthesis bias: again, data synthesis can be negatively affected by the misunderstanding of misinterpretation between researchers. This bias has been reduced by continues discussions between researchers.

\section{CONCLUSION AND FUTURE WORK}

From the previous literature review and the analysis of the extracted data, we gathered all the UX dimensions that have an impact on the UX either during the development or after the product usage. The various aspects that have a direct or indirect impact on the UX have been identified. The relationship between UX dimensions and UX aspects have been also explained.

Several issues are still open for future work, e.g. more work is required to:

1) Developing a framework that combines various UX dimensions, aspects, measurement methods.

2) Build a relationship and integrate the proposed framework with a known maturity model such as CMMI. This will help to strategically improve the UX work level and study in the literature referring to that [30].

3) Study the evaluation methods that can be used to measure the UX aspects of various applications as well as mobile apps.

4) Identify the proper development process that brings more consistency between the proposed framework and the "Development Process" aspect that exists in the "Context" dimension. Currently, no specific process is suggested, while the "Lean UX" is proposed as a UX-centric development process [31] in literature.
5) More analysis in the "Context" dimension is needed to identify more aspects, so it can be related to the remaining dimensions

\section{REFERENCE}

[1] B. Z. Zhao, "A design framework of branded mobile applications," MobileHCI 2014, pp. 507-512, 2014.

[2] S. Khalaf, "The cable industry faces. The perfect storm: Apps, App stores and apple," Flurry Insights, 2015.

[3] S. Rajeshkumar, R. Omar, and M. Mahmud, "Taxonomies of user experience (UX) evaluation methods," in Proc. International Conference on Research and Innovation in Information Systems (ICRIIS), 2013, pp. 533-538.

[4] L. Yong, "User experience evaluation methods for mobile devices," in Proc. 3rd International Conference on Innovative Computing Technology (INTECH), pp. 281-286.

[5] E. Law, "The measurability and predictability of user experience," in Proc. of the 3rd ACM SIGCHI Symposium on Engineering Interactive Computing Systems, pp. 1-10, ACM.

[6] K. Väänänen-vainio-mattila, M. Hassenzahl, C. Landau, and I. Fort, "Towards practical user experience evaluation methods," EL-C. Law, N. Bevan, G. Christou, M. Springett and M. Lárusdóttir, Eds. Meaningful Measures: Valid Useful User Experience Measurement (VUUM), pp. 19-22.

[7] E. L. Law, V. Roto, and M. Hassenzahl, "Understanding, scoping and defining user experience: A survey approach," in Proc. the SIGCHI Conference on Human Factors in Computing Systems, pp. 719-728.

[8] A. Gross and S. Bongartz, "Why do I like it? Investigating the product-specificity of user experience," in Proc. the 7th Nordic Conference on Human-Computer Interaction: Making Sense through Design, pp. 322-330.

[9] ISO 9241-210: 2010 Ergonomics of human-system interaction Part 210: Human-centered design for interactive systems.

[10] D. Tore, B. A. Kitchenham, and M. Jorgensen, "Evidence-based software engineering for practitioners," IEEE Software, vol. 22, no. 1, pp. 58-65, 2005.

[11] K. Staffs. "Guidelines for performing systematic literature reviews in software engineering," Technical Report, Ver. 2.3 EBSE Technical Report, 2007.

[12] M. Alharbi, "User experience dimensions, aspects and measures: Systematic literature review," Master thesis, College of Computer and Infomration Sciences, Prince Sultan University, Riyadh, KSA, 2016.

[13] M. Hassenzahl, "User experience (UX): Towards an experiential perspective on product quality," in Proc. the 20th Conf. on Interaction Homme-Machine, pp. 11-15.

[14] K. Schulze and H. Krömker, "A framework to measure user experience of interactive online products," in Proc. the 7th International Conference on Methods and Techniques in Behavioral Research, p. 14.

[15] H. Jetter and J. Gerken, "A simplified model of user experience for practical application," 2nd Int. Open Work, pp. 106-111, 2007.

[16] S. Moller, K. P. Engelbrecht, C. Kuhnel, I. Wechsung, and B. Weiss, "A taxonomy of quality of service and quality of experience of multimodal human-machine interaction," in Proc. 2009 International Workshop on Quality of Multimedia Experience, 2009, pp. 7-12.

[17] L. Gegner, M. Runonen, and T. Keinonen, "Oscillating between extremes: A framework for mapping differing views on user eXperience," in Proc. the 2011 Conference on Designing Pleasurable Products and Interfaces, 2011.

[18] C. Jian, L. Wenwang, Z. Wenan, G. Haisheng, C. Zhang, and M. Shao-fu, "Customer experience oriented service quality management," in Proc. 2012 IEEE Symposium on Robotics and Applications (ISRA), 2012, pp. 298-301.

[19] V. Fuchsberger, C. Moser, and M. Tscheligi, "Values in action (ViA): Combining usability, user experience and user acceptance," CHI'12 Extend Abstracts on Human Factors in Computing Systems, pp. 1793-1798, 2012.

[20] S. Mahlke, "Understanding users' experience of interaction," in Proc. the 2005 Annual Conference on European Association of Cognitive Ergonomics, pp. 251-254.

[21] S. Moller, K. P. Engelbrecht, C. Kuhnel, I. Wechsung, and B. Weiss, "A taxonomy of quality of service and quality of experience of multimodal human-machine interaction," in Proc. 2009 International Workshop on Quality of Multimedia Experience, 2009, pp. 7-12.

[22] Z. Chen and S. Zhu, "The research of mobile application user experience and assessment model," in Proc. 2011 International 
Conference on Computer Science and Network Technology, 2011, pp. 2832-2835.

[23] N. Fronemann and M. Peissner, "User experience concept exploration: user needs as a source for innovation," in Proc. the 8th Nordic Conference on Human-Computer Interaction: Fun, Fast, Foundational, pp. 727-736.

[24] P. Anitha and B. Prabhu, "Integrating requirements engineering and user experience design in product life cycle management," in Proc. the First International Workshop on Usability and Accessibility Focused Requirements Engineering, pp. 12-17.

[25] C. Gao, S. Wang, and C. Zhong, "Research on user experience evaluation system of information platform based on web environment". in Proc. of 2013 2nd International Conference on Measurement, Information and Control, 2013, pp. 558-562.

[26] S. Sproll, M. Peissner, and C. Sturm, "From product concept to user experience: Exploring UX potentials at early product stages," in Proc the 6th Nordic Conference on Human-Computer Interaction: Extending Boundaries.

[27] H. Väätäjä, T. Koponen, and V. Roto, "Developing practical tools for user experience evaluation: A case from mobile news journalism," in Proc. European Conference on Cognitive Ergonomics: Designing Beyond the Product - Understanding Activity and User Experience in Ubiquitous Environments, 2009.

[28] Kujala and V. Roto, "Identifying hedonic factors in long-term user experience," in Proc. the 2011 Conference on Designing Pleasurable Products and Interfaces, pp. 17, 2011.

[29] T. Dybå, T. Dingsøyr, and G. K. Hanssen, "Applying systematic reviews to diverse study types: An experience report," in Proc. of the First International Symposium on Empirical Software Engineering and Measurement, IEEE Computer Society, 2007, pp. 225-234.

[30] A. L. Peres and S. L. Meira, "Towards a framework that promotes integration between the UX design and SCRUM, aligned to CMMI," in Proc. of 2015 10th Iberian Conference on Information Systems and Technologies (CISTI), pp. 1-4.

[31] L. Liikkanen, H. Kilpiö, L. Svan, and M. Hiltunen, "Lean UX - The next generation of user-centered agile development?" in Proc. the 8th Nordic Conference on Human-Computer Interaction: Fun, Fast, Foundational, pp. 1095-1100

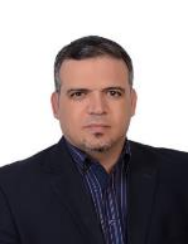

Mohammad Zarour holds a Ph.D in software engineering from École de Technologie Supérieure (ETS) - Université du Québec (Montréal, Canada) and master degree in computer science from University of Jordan.

$\mathrm{He}$ is a professor in the Software Engineering Department at Prince Sultan University, Riyadh, Saudi Arabia. He has over 8 years of experience in teaching in a university environment and has several years of industry experience in information systems development and project management. His research interests include software process assessment and improvement, software quality, cost estimation and web technologies. He has several peer-reviewed publications.

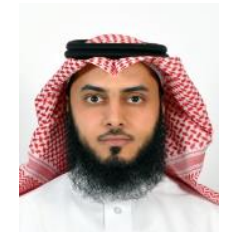

M. Alharbi holds a master degree in software engineering from Prince Sultan University, and bachelor degree in computer science from King Saud University.

$\mathrm{He}$ is a software development manager in Saudi Telecom Company (STC), Riyadh, Saudi Arabia. $\mathrm{He}$ has 12 years of experience in software digital channels solutions development and project management; especially in 